\title{
Publicity Attached to Reputational Incentives: Anti-corruption Models in the Public Administration
}

\author{
Angbonon Eugene Kamalan \\ Department of Economics, Alassane Ouattara University, 28, BP 1694 Abidjan 28, Ivory Coast
}

\begin{abstract}
This article aims at showing how reputational incentives can be used as a powerful mechanism to address corruption. The method derives from Tirole (2009) relating to the effect of rewards on individuals motivation. The article considers rewards as incentives proposed by the principal in a principal-agent model with information asymmetry related to the agent's effort. The purpose of this article is to differentiate the types of incentives between monetary ones and reputational ones. We define an additive separable utility function for the agent by distinguishing between the utility related to the monetary incentive and that related to the reputational incentive. And, we determine the indifference curves of the respective utility function and calculate the marginal rates of substitution. The article provides two main results. First, the study indicates that the change in the attractiveness of monetary incentive from an increase in reputational incentive is negative. This result shows a prosocial effect of reputational incentive that reduces the attractiveness of monetary incentive. That shows the powerful impact of reputational mechanisms as incentive that leads to the probity effort of public administration officials. The other result indicates that the change in the attractiveness of reputational incentive from an increase in monetary incentive is negative. This result shows the harmful effect of the monetary incentive that reduces the attractiveness of the reputational incentive and shows that monetary incentives cannot be used to deal with the greed of individuals. These results are reinforced by the positive marginal substitution rates. The article concludes that reputational and publicity mechanisms are powerful motivators that must be taken into account in the design of costless public policies and administration reforms to address corruption of public officials. Furthermore, monetary incentives should not be used as a tool of addressing corruption.
\end{abstract}

Keywords: Reputational Incentives, Principal-Agent, Corruption

JEL Codes: A13, D73, D78, D82

DOI: $10.7176 / \mathrm{JESD} / 10-8-11$

Publication date: April $30^{\text {th }} 2019$

\section{Introduction}

A key challenge of every public administration is to looking for effective mechanisms that motivate officials for high performing practices. Moreover, the mismatch between the civil servant's selfish pay and other preferences and those of the public administration in terms of performance raises serious problems of motivation of public officials. These problems lead to various temptations: less effort, absenteeism, depression, illness and corruption. These challenges remain at the core of economic research with microeconomic tools developed such us the principal-agent model and the incentives that generate behavioral changes for the agents. The theories of contracts, especially the agency theory (with the principal-agent model) makes clear how these challenges can be met by offering incentives.

The article considers a principal-agent model composed of the government as the Principal and the public officials as Agents. We define the "public official" as any civil servant, official or employee of a country, a state or international agency, a territorial community, a city and to any elected representative, magistrate or person benefiting from the delegation of services from any of such organizations. The principal-agent framework is then commonly used to analyze information asymmetries between the government and the officials and those employed in the public services, since Stiglitz (2000) emphasized the important role of information in avoiding market failures and achieving efficient allocation of resources.

In this article, corruption is going to be considered as a phenomenon that reflect the moral hazard of civil servants and other government employees which develop opportunistic behaviors. Most of works focusing on corruption use different definitions. Nevertheless, several essays use bribery, extortion and fraud as the typical examples of corrupt actions. According to Jain (2001) cited by Toke (2003, 632), "corruption is an act in which the power of public office is used for personal gain in a manner that contravenes the rules of the game". In that case, we consider corruption as a misappropriation of the goods of the State by officials and state workers for personal gain. Several corrupt practices exist, some are presented in Shleifer and Vishny (1993). For example, government officials often collect bribes for providing permits and licenses, for giving passage through customs, or for prohibiting the entry of competitors in sectorial markets, or for the provision of goods and services needed to comply with laws and regulations such as licenses, permits, passports, visas, etc. In these cases they charge personally for goods that the state officially owns.

Historically, different economic theories have been devoted to addressing the phenomenon of corruption, 
from the latter half of the 20th century. Becker and Stigler (1974) have introduced the analysis of corruption with the agency theory. The proponents of agency theory highlighted the role of individuals' calculations about whether or not to engage in or oppose corruption. The "Becker-Stigler" approach consists in raising salaries of public servants in such a way as to increase the opportunity costs of bribery incentives. Subsequently, extended analyses where provided by Klitgaard (1991). Other studies are proposed by Banfield (1975) and Rose-Ackerman (1975). More recently, Lindstedt and Naurin (2010) indicate that transparency, monitoring, and sanctions have deep influence that affect corrupt behavior. Another approach devoted to a comprehensive analysis of the phenomenon of corruption is the one of that proposed by Tullock (2005) dedicated to rent-seeking behavior.

Most of the strategies addressing corruption commonly use the principal-agent understandings, rather than any other alternative view, Persson, Rothstein and Teorell (2013). The method used in this article is based on the framework of Principal-Agent model aiming to show how powerful the reputational incentives are, as they are modelled to be a mechanism to address corruption.

Our model derives from Tirole (2009) relating to the effect of rewards on individuals motivation. For the author, the asymmetry of information between the principal and the agent is focused on the effort that the agent must expend. To extract this hidden information, the principal offers an incentive mechanism that the agent interprets as a reward to be earned after the effort has been revealed. That model of Tirole (Op. cit.) is therefore a signal extraction model. The purpose of this article is to differentiate the types of rewards and earnings between rewards and monetary earnings on one side and rewards and reputational earnings on the other side. Assuming that the gain is constant, we define an additive separable utility function for the agent by distinguishing between the utility related to the monetary incentive and that related to the reputational incentive. Then, we determine the indifference curves of the respective utility function and calculate the marginal rate of substitution.

Two results are obtained. The study indicates that the change in the attractiveness of monetary incentive from an increase in reputational incentive is negative. This result shows a prosocial effect of reputational incentive that reduces the attractiveness of monetary incentive. The other result of the study indicates that the change in the attractiveness of reputational incentive from an increase in monetary incentive in negative. This result shows the harmful effect of monetary incentive that reduces the attractiveness of the reputational incentive.

The article is organized as follows. Section 2 concerns the literature review relating to the role of incentives in economics. Section 3 presents the method and section 4 proposes the findings and comments. Section 5 provides the concluding remarks, limits and perspectives.

\section{Literature Review}

The literature concerns the role of mechanisms on shaping of individuals' behavior. We'll first develop the basic foundations of incentives in economics (2.1) and present the homo oeconomicus effect of incentives on individuals' behavior (2.2).

\subsection{Basic foundations of incentives in economics}

Incentives remain at the very core of thinking in several areas: politics, administration, relationships, education, culture, economics, etc. There has long been a controversy between the views of psychologists and economists about the effects of incentives on individual behavior. The development of incentive theory in economics has historically been an important advance. As far back to Adam Smith, the controversies about the effect of taxation on employment incentives were already strong. The current theory of incentive (Laffont, 2006) focuses on specific objects of microeconomics concerning the behavior of individuals and the set of means used to motivate individuals with private information in many domains: organizations, planning, decentralization and control, regulation, optimal income tax, insurance, pricing of monopolies, public goods, voting, etc. Incentives are thus defined as the set of rules and institutions that induce economic agents to exercise high levels of effort and to correctly transmit all the private information they possess, that is socially relevant to understanding strategic decisions.

Incentives apply to the principal-agent analytical framework and based on the theory of non-cooperative games, but they eliminate the problem of bargaining since the principal proposes the rules of the game and the ability to commit to them as a Stackelberg leader. The purpose of incentives is to induce the agent into revealing the ability to perform a task, i.e. to sincerely reveal the preferences for participation or not in an activity. Equilibria are then obtained in which the agent is the follower with a response function. A better understanding of incentives was needed, especially in the economics of contracts, and this has been formally achieved through Von Neumann and Morgenstern's theory of utility expectation.

\subsection{Homo oeconomicus effect of incentives}

Incentive theory assumes that agents have a substantive economic rationality that is similar to that of homo oeconomicus. The homo oeconomicus effect shows how individuals can be increasingly motivated as the incentive increases. Standard economic approaches to incentives generally assume that incentives such as rewards (monetary 
or material) can increase agents' effort and performance, (Becker and Stigler, 1974). For the motivation to be revealed, a trigger is needed. That's the incentive scheme which can be monetary, material or non-material. Indeed, some individuals are motivation-driven because they are opportunistic or even greedy. So, in an agency relationship, since the principal's interest depends on the success of the agent's action, the principal will therefore present an incentive scheme in order to lead the agent to the success of the task entrusted to him. Since he is rational, the agent will provide more effort to succeed the task for to receive the benefits (rewards). The reward then leads the agent to the Homo oeconomicus behaviour because, the increase in reward increases the effort to succeed in the tasks.

Social norms and mimicry are also key drivers of individual behavior, particularly in the cases involving social interactions, (Kamalan, 2019a, 2019b).

However, psychologists' studies show that incentives can lead to agents' effort reduction, especially in intrinsically motivating activities. Furthermore, recent studies of economists' experiences also share the view of psychologists that incentives (rewards and or punishment) crowd out intrinsic motivation and thus agents' effort (Bénabou and Tirole, 2003).

\section{Methodology}

\subsection{Basic model and variables}

The model is based on a principal (the government) and the public official as the agent. The agent is faced with all the rewards that the principal uses as incentive mechanism on one hand and the corrupt incentives in terms of the utility of participating in an act of corruption only as a corrupted person on the other hand. The model does not take into account the behavior of the agent as a corrupter.

The model seeks to determine the expected utility of the public official who is called upon to perform a task for the administration. The task is the set of public services submitted to the agent on the basis of a contract of delegated discretionary power given by the government. The expected utility of the agent depends on the gain: $V$, the cost of effort in the task: $C$ and the probability of success: $\theta$. The principal has his utility depending on the probability of success in the task and his gain. If there is no effort, i.e. if the probability of success is zero, then the agent has a net disutility related to the effort and the principal has zero utility.

Situations where information is perfect between the principal and the agent regarding the parameters of the contract: cost of effort, probability of success and gains are very uncommon. Rather, asymmetry of information is frequently associated with at least one of the parameters of the contract. In this article, asymmetry refers to the cost of effort. For example, central heads of administration may know whether or not a task assigned to a public official is painful. That is the model of well-informed principal. The agent can have an approximate signal $\sigma$ about the cost of the effort. In this case, the expected utility function of the agent depends on the signal; $\sigma$, the cost of effort: $C$ and the incentive $Y$.

The basic model of the expected utility function of the agent is derived from Tirole (2009) as follows:

$$
E\left(U_{a}\right)=\theta V-E(C \mid \sigma(Y), Y)+\theta Y \geq 0
$$

The variables of this basic model are:

$V$ is the fixed gain the public official earns after performing a task on the basis of a contract. This gain can be material, monetary or reputational,

$\theta$ is the probability of success in the task,

$C$ is the cost of effort the agent makes to the task,

$Y$ is the set of incentives implemented to engage the public official who either accepts or rejects, $\sigma$ is the agent's private information about the hardship or effort required to complete the task,

\subsection{Reputational and monetary views of incentives and gains}

The model of Tirole can be adapted for our study in two ways. First, Tirole (Op. cit.) analyses incentives in an aggregate way when it could have different types of incentives with their specific influence on the behavior of public officials. Incentives can be divided into two categories: reputational incentives and monetary ones.

Reputational incentives include any non-monetary reward, whether material (decoration, medal, honor roll) or non-material (promotion, advertising, etc.). These awards produce a satisfaction in terms of distinction, notoriety and prestige. The other category is monetary incentive, which includes salary and any reward in terms of financial payment and provides monetary gratification. $y=y\left(y_{r}, y_{m}\right) . y_{r}$ represents the attractiveness of reputational incentive and $y_{m}$ represents the attractiveness of the monetary incentive.

Second, we consider $V$ is a fixed gain earned by the public official, taken as the sum of reputational gain related to the publicity noted $v_{r}$ and the wage noted $v_{m} . V$ has previously been supposed to be aggregated when it could have different types of gains with their specific influence on the behavior of public officials. Gains can be divided into two categories: reputational gains and monetary ones. $V=V\left(v_{r}, v_{m}\right)$.

$v_{r}$ is the gain in terms of reputation for the agent at the unit level, resulting from the execution of the task. It 
is an opinion about the agent, consistently limited to a limited number of people (co-workers) who have the information about the skills. That opinion is not revealed to the public. Let's have an example of the situation where the boss (principal) is the only one who knows the ability to succeed in the task repeatedly by the agent. So, the gain in terms of reputational opinion is limited between the boss and the agent in a constant way. This opinion (or reputational gain) may vary, when the principal decides to reveal to the public through reputational incentives such as publicity.

The variables of the basic model are then extended as follows:

$y_{r}$ is a function relating to the attractiveness of reputational incentive when disaggregating $Y$. It is a gain in terms of social approval and admiration of others. In the modelling, $y_{r}$ is an indifference curve,

$y_{m}$ is a function relating to the attractiveness of the monetary incentive when $Y$ is disaggregated. It's a bonus added to the agent's salary. In the modelling, $y_{r}$ is an indifference curve,

$v_{r}$ is the gain in terms of reputation. It is a fixed component of $V$, related to publicity,

$v_{m}$ is the fixed monetary gain used as a component of $V$, related to wage,

$U_{r}$ is the utility function of reputational incentive,

$U_{m}$ is the utility function of monetary incentive,

Let's note $v_{r}$ and $v_{m}$ are independent of $y_{r}$ and $y_{m}$.

The basic model becomes:

$$
\begin{gathered}
E\left(U_{a}\right)=\theta \underbrace{\left(v_{r}+v_{m}\right)}_{V}-\underbrace{\left[\mathrm{E}\left(\mathrm{c} \mid \sigma\left(y_{r}\right), y_{r}\right)+\mathrm{E}\left(\mathrm{c} \mid \sigma\left(y_{m}\right), y_{m}\right)\right]}_{E(c \mid \sigma(Y), Y)}+\theta \underbrace{\left(y_{r}+y_{m}\right)}_{Y} \geq 0 \\
E\left(U_{a}\right)=\theta v_{r}+\theta v_{m}-\mathrm{E}\left(\mathrm{c} \mid \sigma\left(y_{r}\right), y_{r}\right)-\mathrm{E}\left(\mathrm{c} \mid \sigma\left(y_{m}\right), y_{m}\right)+\theta y_{r}+\theta y_{m} \geq 0 \\
E\left(U_{a}\right)=\theta v_{r}+\theta v_{m}-\mathrm{E}\left(\mathrm{c} \mid \sigma\left(y_{r}\right), y_{r}\right)+\theta y_{r}-\mathrm{E}\left(\mathrm{c} \mid \sigma\left(y_{m}\right), y_{m}\right)+\theta y_{m} \geq 0 \\
E\left(U_{a}\right)=\left[\theta v_{r}-\mathrm{E}\left(\mathrm{c} \mid \sigma\left(y_{r}\right), y_{r}\right)+\theta y_{r}\right]+\left[\theta v_{m}-\mathrm{E}\left(\mathrm{c} \mid \sigma\left(y_{m}\right), y_{m}\right)+\theta y_{m}\right] \geq 0 \\
E\left(U_{a}\right)=\underbrace{\left[\theta v_{r}-\mathrm{E}\left(\mathrm{c} \mid \sigma\left(y_{r}\right), y_{r}\right)+\theta y_{r}\right]}_{E\left(U_{r}\left(y_{r}\right)\right)}+\underbrace{\left[\theta v_{m}-\mathrm{E}\left(\mathrm{c} \mid \sigma\left(y_{m}\right), y_{m}\right)+\theta y_{m}\right]}_{\mathrm{E}\left(\mathrm{U}_{m}\left(y_{m}\right)\right)} \geq 0 \\
E\left(U_{r}\right)=\theta\left(v_{r}+y_{r}\right)-\mathrm{E}\left(\mathrm{c} \mid \sigma\left(y_{r}\right), y_{r}\right) \\
E\left(U_{m}\right)=\theta\left(v_{m}+y_{m}\right)-\mathrm{E}\left(\mathrm{c} \mid \sigma\left(y_{m}\right), y_{m}\right)
\end{gathered}
$$

The expected utility function of the public official is additive and separable with ( $3 a)$ and ( $3 b)$.

Since $v_{m}$ and $v_{r}$ are constant, we have:

$$
E\left(U_{a}\left(y_{r}, y_{m}\right)\right)=E\left(U_{r}\left(y_{r}\right)\right)+\mathrm{E}\left(\mathrm{U}_{m}\left(y_{m}\right)\right) \geq 0
$$

3.3 Optimal decision of the agent and indifference curves

The agent will perform a task if his information about the cost of effort exceeds $\sigma^{*}(\mathrm{y})$ as follows

$$
\begin{gathered}
E\left(U_{a}^{*}\right)=\left[\theta v_{r}-\mathrm{E}\left(\mathrm{c} \mid \sigma^{*}\left(y_{r}\right), y_{r}\right)+\theta y_{r}\right]+\left[\theta v_{m}-\mathrm{E}\left(\mathrm{c} \mid \sigma^{*}\left(y_{m}\right), y_{m}\right)+\theta y_{m}\right]=0 \\
E\left(U_{a}^{*}\right)=\underbrace{\left[\theta v_{r}-\mathrm{E}\left(\mathrm{c} \mid \sigma^{*}\left(y_{r}\right), y_{r}\right)+\theta y_{r}\right]}_{E\left(U_{r}^{*}\right)}+\underbrace{\left[\theta v_{m}-\mathrm{E}\left(\mathrm{c} \mid \sigma^{*}\left(y_{m}\right), y_{m}\right)+\theta y_{m}\right]}_{E\left(U_{m}^{*}\right)}=0 \\
E\left(U_{a}^{*}\right)=\theta v_{r}-\mathrm{E}\left(\mathrm{c} \mid \sigma^{*}\left(y_{r}\right), y_{r}\right)+\theta y_{r} \\
E\left(U_{m}^{*}\right)=\theta v_{m}-\mathrm{E}\left(\mathrm{c} \mid \sigma^{*}\left(y_{m}\right), y_{m}\right)+\theta y_{m}
\end{gathered}
$$

Let's define the indifference curves.

Suppose $E\left(U_{a}^{*}\left(y_{r}, y_{m}\right)\right)=U_{a}=U_{a}{ }^{0}$ is the utility obtained by the public official while $\sigma^{*}(\mathrm{y})$ is known as proposed in (6). That supposes $U_{a}{ }^{0}$ is at a fixed level, so we can write: $U_{a}{ }^{0}=U_{a}\left(y_{r}, y_{m}\right)$

The advantage is that we can derive the indifference curves.

$$
\begin{gathered}
y_{r}=y_{r}\left(U_{a}{ }^{0}, y_{m}\right) \\
y_{m}=y_{m}\left(y_{r}, U_{a}{ }^{0}\right)
\end{gathered}
$$

These indifference curves are the functions of attractiveness of reputational incentives and monetary incentives respectively. They represent the strength of each incentive mechanism in terms of attractiveness for the public official. The question is then to know how the public official will substitute one incentive for the other while maintaining the level of utility and how the attractiveness of one form of incentive would be affected when the other form of incentive is varying.

\section{Findings and Discussion}

The results of the model are provided by the slopes of indifference curves and the marginal rates of substitution.

\subsection{Slopes of indifference curves}

Let's look for the slope of the first indifference curve proposed in (7): $y_{r}=y_{r}\left(U_{a}{ }^{0}, y_{m}\right)$, i.e. we have to find: $\frac{d y_{r}}{d y_{m}}$ 
We have: $U_{a}{ }^{0}=U_{a}\left(y_{r}\left(U_{a}{ }^{0}, y_{m}\right), y_{m}\right)$

$$
\begin{gathered}
d U_{a}^{0}=0=>\frac{\partial U_{a}}{\partial y_{m}} d y_{m}+\frac{\partial U_{a}}{\partial y_{r}} \frac{d y_{r}}{d y_{m}} d y_{m}=0 \\
=>\left(\frac{\partial U_{a}}{\partial y_{m}}+\frac{\partial U_{a}}{\partial y_{r}} \frac{d y_{r}}{d y_{m}}\right) d y_{m}=0 \\
=>\frac{\partial U_{a}}{\partial y_{m}}+\frac{\partial U_{a}}{\partial y_{r}} \frac{d y_{r}}{d y_{m}}=0 \\
=>\frac{d y_{r}}{d y_{m}}=-\frac{\partial / \partial y_{m}}{\partial U_{a} / \partial y_{r}} \\
=>\frac{d y_{r}}{d y_{m}}=-\frac{\partial U_{a}}{\partial y_{m}} \times \frac{\partial y_{r}}{\partial U_{a}} \\
=>\frac{d y_{r}}{d y_{m}}=-\frac{\partial y_{r}}{\partial y_{m}} \times \frac{\partial U_{a}}{\partial U_{a}} \\
=>\frac{d y_{r}}{d y_{m}}=-\frac{\partial y_{r}}{\partial y_{m}} \\
=>\frac{d y_{r}}{d y_{m}}=-\frac{\partial y_{m}}{\partial U_{a} / \partial y_{r}}=-\frac{U_{m}^{\prime}}{U_{r}^{\prime}}
\end{gathered}
$$

$\frac{d y_{r}}{d y_{m}}$ represents the slope of the indifference curve of $y_{r}=y_{r}\left(y_{m}, U_{a}{ }^{0}\right)$

$$
\frac{d y_{r}}{d y_{m}}<0
$$

Let's look for the slope of the second indifference curve proposed in (8): $y_{m}=y_{m}\left(y_{r}, U_{a}{ }^{0}\right)$, i.e. we have to find: $\frac{d y_{m}}{d y_{r}}$

We have: $U_{a}^{0}=U_{a}\left(y_{r}, y_{m}\left(y_{r}, U_{a}^{0}\right)\right)$

$$
\begin{gathered}
d U_{a}^{0}=0=>\frac{\partial U_{a}}{\partial y_{r}} d y_{r}+\frac{\partial U_{a}}{\partial y_{m}} \frac{d y_{m}}{d y_{r}} d y_{r}=0 \\
=>\left(\frac{\partial U_{a}}{\partial y_{r}}+\frac{\partial U_{a}}{\partial y_{m}} \frac{d y_{m}}{d y_{r}}\right) d y_{r}=0 \\
=>\frac{\partial U_{a}}{\partial y_{r}}+\frac{\partial U_{a}}{\partial y_{m}} \frac{d y_{m}}{d y_{r}}=0 \\
=>\frac{d y_{m}}{d y_{r}}=-\frac{\partial / \partial y_{r}}{\partial U_{a} / \partial y_{m}} \\
=>\frac{d y_{m}}{d y_{r}}=-\frac{\partial U_{a}}{\partial y_{r}} \times \frac{\partial y_{m}}{\partial U_{a}} \\
=>\frac{d y_{m}}{d y_{r}}=-\frac{\partial y_{m}}{\partial y_{r}} \times \frac{\partial U_{a}}{\partial U_{a}} \\
=>\frac{d y_{m}}{d y_{r}}=-\frac{\partial y_{m}}{\partial y_{r}} \\
\frac{d y_{m}}{d y_{r}}=-\frac{\partial y_{r}}{\partial U_{a} / \partial y_{m}}=-\frac{U_{r}^{\prime}}{U_{m}^{\prime}}
\end{gathered}
$$

$\frac{d y_{m}}{d y_{r}}$ represents the slope of the indifference curve of $y_{m}=y_{m}\left(y_{r}, U_{a}{ }^{0}\right)$

$$
\frac{d y_{m}}{d y_{r}}<0
$$

\subsection{Marginal rates of substitution}

Let's look for the marginal rates of substitution. Equation (9) and (10) have provided the marginal utilities $U_{r}^{\prime}$ and $U_{m}^{\prime}$. In fact, $\frac{\partial U_{a}}{\partial y_{r}}=U_{r}^{\prime}$ and $\frac{\partial U_{a}}{\partial y_{m}}=U_{m}^{\prime}$

$\frac{U_{r}^{\prime}}{U_{m}^{\prime}}$ reflects the relative marginal utility of the reputational incentive compared to the monetary incentive. This is 
therefore the marginal rate of substitution of the reputational incentive by the monetary incentive.

$$
\begin{aligned}
\text { We have: }-\frac{U_{r}^{\prime}}{U_{m}^{\prime}}= & -\mathrm{TMS}_{y_{r} y_{m}}=\frac{d y_{m}}{d y_{r}} \\
& \text { so the } \mathrm{TMS}_{y_{r} y_{m}}=-\frac{d y_{m}}{d y_{r}}>0
\end{aligned}
$$

$\frac{U_{m}^{\prime}}{U_{r}^{\prime}}$ represents the relative marginal utility of monetary incentive compared to reputational incentive, i.e. the marginal rate of substitution of monetary incentive by reputational incentive.

$$
\begin{aligned}
\text { We have: }-\frac{U_{m}^{\prime}}{U_{r}^{\prime}}=-\mathrm{TMS}_{y_{m} y_{r}}=\frac{d y_{r}}{d y_{m}} \\
\\
\text { so the } \mathrm{TMS}_{y_{m} y_{r}}=-\frac{d y_{r}}{d y_{m}}>0
\end{aligned}
$$

These findings invite some comments:

According to the indifference curve of reputational incentive given in (7), the results indicate that $\frac{d y_{r}}{d y_{m}}<0$ as seen in (9) and $\mathrm{TMS}_{y_{r} y_{m}}=-\frac{d y_{m}}{d y_{r}}>0$ seen in (11). The results relating to monetary incentive concern the slope of the indifference curve $\frac{d y_{m}}{d y_{r}}<0$ proposed in (10) and $\mathrm{TMS}_{y_{m} y_{r}}=-\frac{d y_{r}}{d y_{m}}>0$ in (12).

The results concerning the marginal utilities of reputational or monetary incentives aim to determine the degree of incentive mechanism that the public official is willing to seek. The study shows that marginal utilities of reputational and monetary incentives are positive and this occurs when the search for an additional form of incentive increases the total utility of the public official. Marginal rates of substitution represent the value of an incentive mechanism that the public official is willing to give up for another incentive, as long as the new incentive is equally satisfying. Since marginal substitution rates are positive, public officials may be rationally led to substitute one incentive mechanism for another in order to maintain the same level of utility. In this case, what is of importance is the sign of the slope of the indifference curves.

\section{Concluding remarks, limits and perspectives}

The study indicates that the change in the attractiveness of monetary incentive from an increase in reputational incentive is negative. This result shows a prosocial effect of reputational incentive that reduces the attractiveness of monetary incentive. That shows the powerful impact of reputational incentive as mechanism that leads to the probity effort of public administration officials. Such a result, which is close to that of the crowding out effect, may indicate a high intrinsic motivation of administrative officers. Reputational incentive can then be used as a tool of addressing corruption. The other result of the study indicates that the change in the attractiveness of reputational incentive from an increase in monetary incentive in negative. This result shows the harmful effect of monetary incentive that reduces the attractiveness of the reputational incentive. Monetary incentives cannot be used to deal with the issue of individuals' greed. They're to not be used as an anti-corruption tool. These results are reinforced by the positive marginal rates of substitution. The article concludes that reputational and publicity mechanisms are powerful motivators that must be taken into account in the design of costless public policies and administration reforms to address corruption of public officials. Furthermore, monetary incentives should not be used as a tool of addressing corruption.

Our study is limited in one important point. We've considered the basic asymmetric model of Tirole (2009) in which, incentives $(Y)$ are granted by a benevolent and infallible principal. However, after having disaggregated $(Y)$ by $y_{r}+y_{m}$, our derived model considers that the two variants of $(Y)$ can be provided by the principal and by other third parties including corrupters. But we're not in a framework of multi-principal-agent. So, our model must move to a pure arbitration approach in which the public official chooses the corrupt incentives from the briber or chooses the reputational incentive by rejecting the corruption.

\section{References}

Banfield, E. (1975), "Corruption as a feature of government organization”, Journal of Law and Economics, XVIII (1975), 587-605.

Becker, G. \& George S. (1974), "Law enforcement, malfeasance and the compensation of enforcers", Journal of Legal Studies, III, (1974), 1-19.

Bénabou, R. \& Tirole, J. (2003), “Intrinsic and extrinsic motivation”, The Review of Economic Studies,70(3):489520.

Kamalan, E. (2019a), "Economic incentives and social norms can lead actors to prosocial behavior: an evidencebased framework and findings", Advances in Politics and Economics, 2(1):23-37.

Kamalan, E. (2019b), "Economics and sociological foundations of prosocial behavior: A theoretical survey", American Journal of Humanities and Social Sciences Research, 3(1):164-168.

Klitgaard, Robert (1991), Gifts and Bribes, Richard Zeckhauser Ed. Strategy and Choice, Cambridge, MA: MIT Press. 
Laffont, J-J. (2006), “À propos de l'émergence de la théorie des incitations”, Revue Française de Gestion, 160(1):177-189.

Lindstedt, C. \& Naurin, D. (2010), “Transparency is not enough: making transparency effective in reducing corruption", International Political Science Review, 31(3):301-322.

Persson, A., Rothstein, B., \& Teorell, J. (2013), "Why anticorruption reforms fail-systemic corruption as a collective action problem", Governance, 26(3):449-471

Rose-Ackerman, S. (1975), "The economics of corruption", Journal of Public Economics, 4(2):187-203

Shleifer, A. \& Vishny, W. (1993), "Corruption”, The Quarterly Journal of Economics, 108(3):599-617

Stiglitz, J. (2000), "The contributions of the economics of information to twentieth century economics", Quarterly Journal of Economics, 115(4):1441-78.

Tirole, J. (2009), "Motivation intrinsèque, incitations et normes sociales”, Revue Economique, 60(3):577-589

Toke, A. (2003), "Economic Analysis of Corruption: a Survey", The Economic Journal, 491(113):632-652.

Tullock, G. (2005), The Rent-Seeking Society, The selected works of Gordon Tullock. vol. 5, Publisher Liberty Fund, 342 page 